\title{
Action of verapamil on sinus node, atrioventricular, and intraventricular conduction
}

\author{
M. H. Husaini ${ }^{1}$, J. Kvasnicka ${ }^{2}$, L. Rydén, and S. Holmberg \\ From Medical Clinic I, Section of Cardiology, Sahlgren's Hospital, Göteborg, Sweden
}

Verapamil, though originally introduced as an antianginal drug, seems to have its most interesting properties when used to treat supraventricular tachyarrhythmias. In clinical practice it has been noted that the drug prolongs $A V$ conduction time. To study this in more detail electrocardiograms and His bundle electrograms were recorded.

It is concluded that verapamil prolongs $A V$ conduction proximal to the bundle of His, probably due to an intrinsic action. This may explain its action in some cases of paroxysmal supraventricular arrhythmia.

Verapamil was introduced into clinical practice as a coronary vasodilator (Haas and Härtfelder, 1962) and originally used as an antianginal drug (Neumann and Luisada, 1966; Sandler, Clayton, and Thornicraft, 1968). Though its effectiveness as an antianginal drug remains controversial it was soon found that verapamil had antiarrhythmic properties especially in patients with supraventricular tachyarrhythmias (Melville, Shister, and Huq, 1964; Bender, 1967; Diewitz and Lange, 1969; Schamroth, I97I; Schamroth, Krikler, and Garrett, 1972).

In clinical practice it has been shown to decrease atrioventricular conductivity (Bender and Zimmerhof, 1967; Diewitz and Lange, 1969; Rydén and Saetre, I97I). The present study was designed to look at this property more closely and to elucidate the mode of antiarrhythmic action of verapamil.

\section{Subjects and methods}

Ten patients, aged 35 to 68 years, with various forms of heart disease had His bundle electrogram studies as part of their routine investigation on account of a history of some cardiac arrhythmia. All patients were in sinus rhythm without heart failure. The atrioventricular conduction time was within normal limits in all patients except one (PQ $0.24 \mathrm{sec}$ ) who was the only one receiving digitalis. Seven patients were investigated while not being treated by any other drug. In the remaining three, verapamil was administered after beta-blockade and atropine. Informed consent was obtained from all patients.

Received 20 December 1972.

1 Present address: Ashton-under-Lyne General Hospital. 2 Present address: Medical Clinic I, Fakulté Nemocnice, Kunz, Hradec, Kraloué, Czechoslovakia.
His bundle electrograms were obtained as described by Scherlag et al. (1969) using a bipolar electrodecatheter (USCI C5I 6F). Right atrial pacing was performed via a bipolar electrode positioned close to the sinus node. Drugs were administered via a polythene cannula introduced in an arm vein. Mepivacaine I per cent was used as a local anaesthetic.

The study was started after a 20-minute resting period following the diagnostic procedure. Filtered $(50-400 \mathrm{~Hz})$ and unfiltered His bundle electrograms and surface electrocardiograms were recorded on a batterypowered three-channel Mingograf (EM 34, ElemaSchönander) at a paper speed of $100 \mathrm{~mm} / \mathrm{sec}$. After a rosecond record during spontaneous rhythm, atrial pacing was started at a rate of $100 / \mathrm{min}$ (AP IOO) for 20 seconds, the last 10 of which were recorded. Then the pacing rate was increased to $130 / \mathrm{min}$ (AP 130), and again a rosecond long record was made after Io seconds of pacing. Finally the pacemaker was switched off while continuing to record during return of sinus node activity. After obtaining two such records at 5 -minute intervals, verapamil $0.15 \mathrm{mg} / \mathrm{kg}$ body weight was injected intravenously over a 2-minute period and further records were obtained at 2, 5, 10, 15, and 20 minutes after the start of injection. In 4 out of 7 patients $\mathrm{I} \mathrm{mg}$ atropine was given intravenously after the 20-minute record and a further registration obtained 3 minutes after atropine. One of the patients being treated by beta-blockade received alprenolol $100 \mathrm{mg}$ four times daily, the last dose being given 2 hours before the study. The other 2 were given practolol $30 \mathrm{mg}$ intravenously before the study. After obtaining 2 post beta-blockade records at 5-minute intervals, $\mathrm{I}$ mg atropine was injected intravenously. Three minutes later another record was obtained and then verapamil was given. Post-verapamil records were obtained at the times given above. Twelve minutes after verapamil another $0.5 \mathrm{mg}$ atropine was given intravenously.

All records were analysed as follows: 
I) $\mathrm{PH}$, i.e. the interval between the beginning of the $\mathbf{P}$ wave on the electrocardiogram and the onset of the $H$ deflection on the His bundle electrogram.

2) $\mathrm{StH}$, i.e. the interval between pacemaker-induced artefact and $\mathrm{H}$ deflection.

3) $\mathrm{HQ}$ and $\mathrm{HS}$, i.e. the intervals between the onset of $H$ on the His bundle electrogram and, respectively, the onset and end of the QRS on the electrocardiogram.

4) StP, i.e. the interval between pacemaker-induced artefact and end of intra-atrial $P$ wave on the His bundle electrogram (measured only at AP roo).

5) $R R$ interval during spontaneous rhythm.

6) Corrected sinus recovery time, i.e. the difference between the last pacing artefact to the first spontaneous $P$ and the prepacing PP interval at that time.

All intervals were expressed in milliseconds. The results were analysed using Student's t test' for paired differences.

\section{Results}

After verapamil there was a continuous increase in the $\mathrm{PH}$ interval during spontaneous rhythm and the StH interval during AP 100. Maximal prolongation was reached at Io minutes after drug administration, the mean increase \pm SE of $\mathrm{PH}$ was $28 \pm 12 \cdot 3$ msec $(P<0.01)$ and of the StH $74 \pm 29.2 \mathrm{msec}$ $(\mathbf{P}<0.01$ ) (Fig. I). In one of the patients verapamil induced a second-degree AV block above the level of His during AP roo.

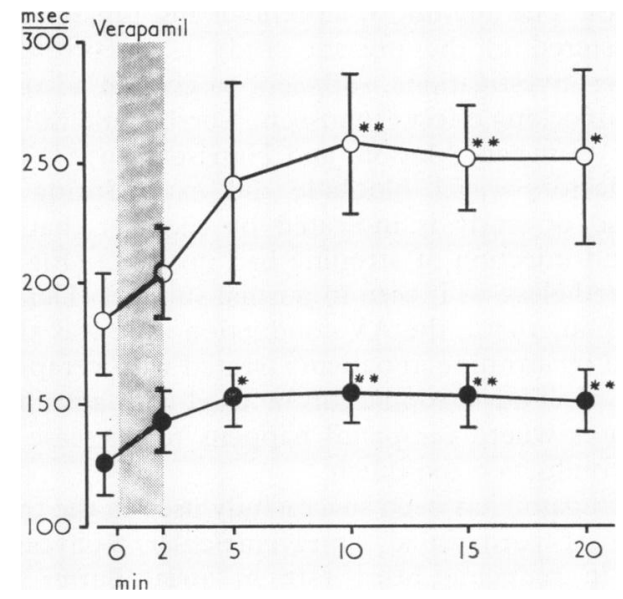

FIG. I Changes in P-His interval (O) during spontaneous rhythm and stimulus-His interval $(\bigcirc)$ during atrial paced rate $100 / \mathrm{min}$ after administration of verapamil $0.15 \mathrm{mg} / \mathrm{kg}$ body weight. Mean values for the group $\pm S E .{ }^{\star}=P<0.02,{ }^{\star}=P<0.01$. In this and the other Figures time in minutes is on the $x$-axis while $P$-His and/or stimulus-His intervals in msec are on the $y$-axis.
During AP I30 verapamil induced a similar type of second-degree block in 5 out of 7 patients. In one patient in whom, during AP 130, this type of AV block was already present before verapamil administration, the degree of AV block was increased. In the seventh patient the $\mathrm{StH}$ interval was prolonged from 160 to $240 \mathrm{msec}$.

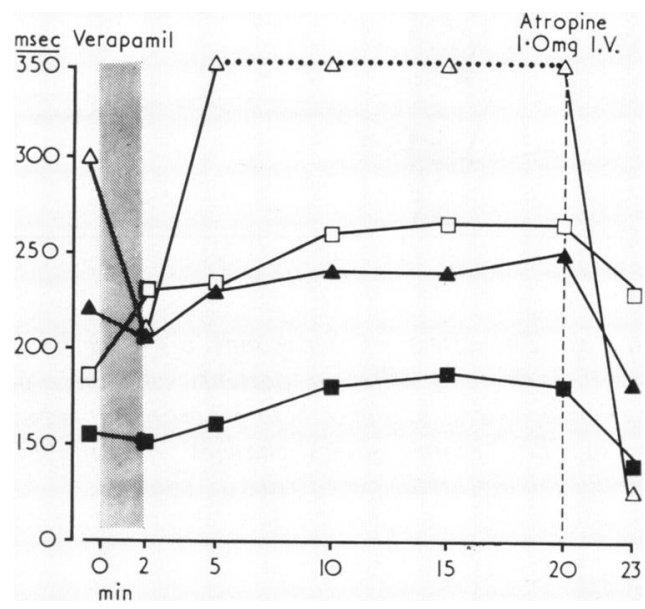

FIG. 2 The effect of atropine on verapamil induced increase of stimulus-His interval during atrial paced rate at 100/min. The results in 4 different patients are shown, patients being indicated with varying symbols. Dotted line means $A V$ block of second-degree, site of blockage above the level of His.

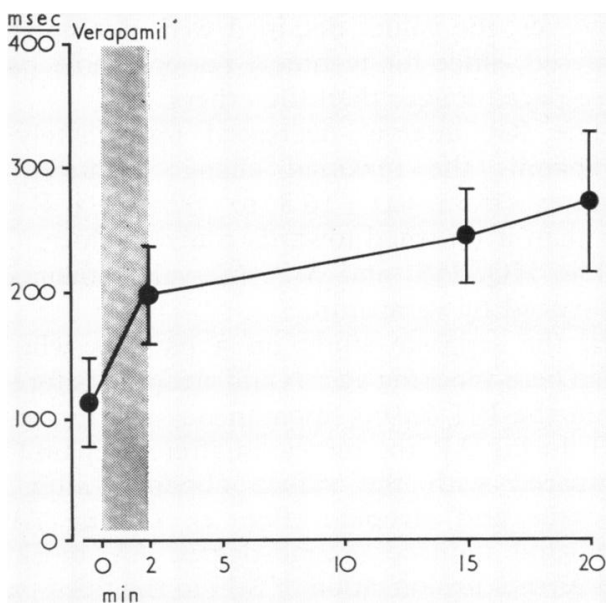

FIG. 3 Changes in corrected sinus recovery time (see text for explanation) after administration of verapamil $0.15 \mathrm{mg} / \mathrm{kg}$ body weight. Mean values of the group $\pm S E$. 


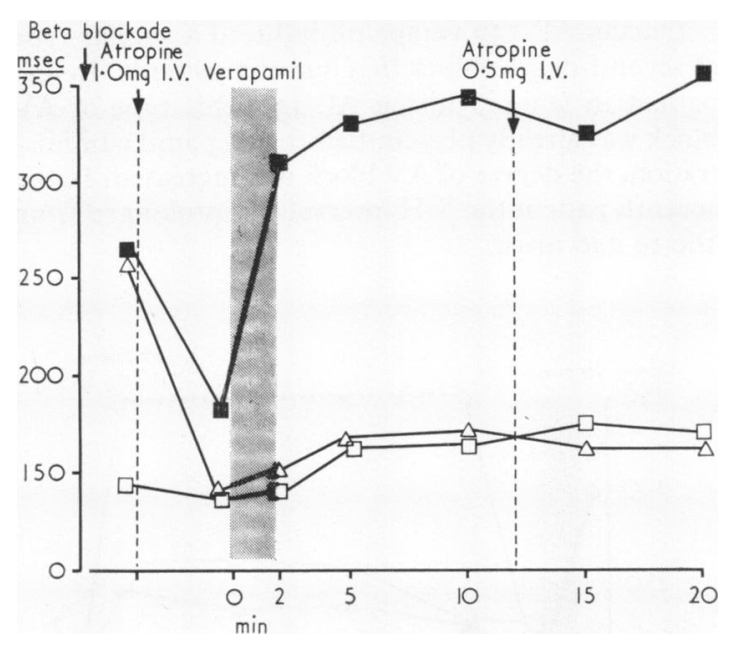

FIG. 4 The effect of verapamil $0.15 \mathrm{mg} / \mathrm{kg}$ body weight given to 3 different patients who were given beta-blockers and atropine before verapamil administration. The Figure shows changes in stimulus-His interval during atrial paced rate at 100/min.

In the 4 patients in whom atropine was administered 20 minutes after verapamil PH as well as StH intervals considerably decreased when compared to the values measured immediately before atropine (Fig. 2). Second-degree AV block was present in these patients at AP 130 but was reversed to firstdegree block after atropine.

The corrected sinus recovery time increased in all patients except one where it was unchanged (Fig. 3). However, the values obtained were not statistically analysed, since for technical reasons some patients were paced longer than the others.

The $R R$ interval decreased immediately after verapamil; the maximal change occurred at 5 minutes (from $94 \mathrm{I} \pm 16.8$ to $780 \pm 42.3 \mathrm{P}<0.02$ ) but then it returned towards control values.

The HQ, HS, and StP intervals remained uninfluenced by verapamil.

In the separate study on 3 patients who were given beta-blocking agents and atropine before verapamil the $\mathrm{PH}$ during spontaneous rhythm and the StH during AP-roo increased after verapamil when compared with the values obtained after betablockade and atropine (Fig. 4). During AP I30 verapamil induced second-degree AV block in 2 and further prolongation of StH in the third patient. The second injection of atropine (12 minutes after verapamil) did not improve a suppressed AV conduction. The HQ and HS intervals again remained unaffected.

\section{Discussion}

Bender and Zimmerhof (1967) were the first to observe a second-degree AV block after treatment with verapamil. Later on other reports of increased $\mathrm{AV}$ conduction time after verapamil have appeared (Brichard and Zimmermann, 1970; Bass and Friedemann, 1971; Rydén and Saetre, 1971). An investigation of AV conductivity using His bundle electrograms was performed by Neuss and Schlepper (197I). They found a prolongation of AV conduction presumably within the AV node. Our results are in accordance with this study. Bass and Friedemann (197I) stated that there was a prolongation of intra-atrial conduction after verapamil. This statement is not confirmed by our finding of an unchanged StP interval, which indicates that intraatrial conduction is not influenced by the drug. The results of the study by Neuss and Schlepper (I97I) are in accord with ours. Furthermore, Singh and Vaughan Williams (1972) in a study on rabbit atria found that increasing concentrations of verapamil increased the conduction velocity through the atria.

Animal studies suggest that the action of verapamil on the sinus and AV nodes is due to both a direct cardiac effect and an antagonism of vagal activity (Garvey, 1969). To our knowledge these conclusions have not been verified by studies in human beings. Our results on those patients who had been pretreated with a beta-blocker and atropine seem to indicate that even in humans verapamil has an intrinsic action not mediated by autonomic nerves. The amount of alprenolol and practolol administered in the present study is, according to earlier investigations, sufficient to give an adequate beta-blocking effect (Johnsson, Norrby, and Sölvell, 1967; Finegan, Marlon, and Harrison, 1972). That satisfactory vagal blockade did exist during the period of study is indicated by the fact that the second injection of atropine had no effect (Fig. 4). Nevertheless, as is seen in normal subjects (Damato and Lau, 1970), the AV conduction time was shortened by atropine in patients treated with verapamil (Fig. 2). Thus atropine can be used with advantage in cases where verapamil happens to decrease the $\mathrm{AV}$ conduction too much.

Verapamil has been successfully used in the treatment of paroxysmal supraventricular tachycardia and in reducing heart rate in atrial flutter and fibrillation (Bender, 1967; Schamroth, I97I; Schamroth et al., 1972). Since paroxysmal supraventricular tachycardias are currently believed to be perpetuated by re-entry within the AV node (Goldreyer and Bigger, 1969; Goldreyer and Damato, 1971) and the ventricular rate in atrial flutter and fibrillation is dependent on AV conductivity, the depressant effect of the drug on AV conduction 
explains the effect of verapamil upon these conditions.

Some prolongation of corrected sinus recovery time in our series is in line with the results of animal studies performed by Garvey (1969) and Singh and Vaughan Williams (1972) who noted suppression of spontaneous atrial rate after administration of verapamil. Until further studies in human beings elucidate this, verapamil should perhaps be used with caution in patients with sick sinus syndrome, who may present with supraventricular tachycardia.

\section{References}

Bass, O., and Friedemann, M. (1971). Ein Beitrag zum antiarrhythmischen Wirkungsmechanismus von Verapamil (Isoptin). Schweizerische medizinische Wochenschrift, I0I, 792.

Bender, F., (1967). Isoptin zur Behandlung der tachykarden Form des Vorhofflatterns. Medizinische Klinik, 62, 634.

Bender, F., and Zimmerhof, K. (1967). Wenckebachsche Periode als Zeichen der Uberdosierung eines Mittels mit sympathikolytischer Herzwirkung. Medizinische Welt, I, 1585.

Brichard, G., and Zimmermann, P. E. (1970). Verapamil in cardiac dysrhythmias during anaesthesia. British fournal of Anaesthesia, 42, 1005.

Damato, A. N., and Lau, S. H. (1970). Clinical value of the electrogram of the conduction system. Progress in Cardiovascular Diseases, 13, II 9.

Diewitz, M., and Lange, B. M. (1969). Zur Behandlung tachykarder Rhythmusstörungen mit Verapamil. Medizinische Klinik, 64, 1699.

Finegan, R. E., Marlon, A. M., and Harrison, D. C. (1972). Circulatory effects of practolol. American fournal of Cardiology, 29, 315.

Garvey, H. L. (1969). The mechanism of action of verapamil on the sinus and AV nodes. European fournal of Pharmacology, 8, I 59.

Goldreyer, B. N., and Bigger, J. T., Jr. (1969). Spontaneous and induced reentrant tachycardia. Annals of Internal Medicine, 70, 87.

Goldreyer, B. N., and Damato, A. N. (197I). The essential role of atrioventricular conduction delay in the initiation of paroxysmal supraventricular tachycardia. Circulation, 43, 679 .
Haas, H., and Härtfelder, G. (1962). $\alpha$-Isopropyl- $\alpha-[(\mathrm{N}-$ methyl-N-homoveratryl)- $\gamma$-amino-propyl]-3.4-dimethoxyphenylacetonitril, eine Substanz mit coronargefässerweiternden Eigenschaften. Arzneimittel Forschung, 12, 549.

Johnsson, G., Norrby, A., and Sölvell, L. (1967). Potency and time-effect relationship in man of propranolol and $\mathrm{H} \mathbf{5 6 / 2 8}$. I. Comparative studies after intravenous administration. II. Studies on the ratio of equipotent oral and intravenous doses. Acta Pharmacologica et Toxicologica, 25, Suppl. 2, 95.

Melville, K. I., Shister, H. E., and Huq, S. (1964). Iproveratril: experimental data on coronary dilatation and antiarrhythmic action. Canadian Medical Association fournal, 90, 76r.

Neumann, M., and Luisada, A. A. (1966). Double blind evaluation or orally administered iproveratril in patients with angina pectoris. American fournal of the Medical Sciences, $251,552$.

Neuss, H., and Schlepper, M. (1971). Der Einfluss von Verapamil auf die atrio-ventrikuläre Uberleitung. Lokalisation des Wirkungsortes mit His-Bündel Elektrogrammen. Verhandlungen der Deutschen Gesellschaft für Kreislaufforschung, 37, 433.

Rydén, L., and Saetre, H. (1971). The haemodynamic effect of verapamil. European fournal of Clinical Pharmacology, 3, 153.

Sandler, G., Clayton, G. A., and Thornicraft, S. G. (1968). Clinical evaluation of verapamil in angina pectoris. British Medical fournal, 3, 224.

Schamroth, L. (I97I). Immediate effects of intravenous verapamil on atrial fibrillation. Cardiovascular Research, 5, 419.

Schamroth, L., Krikler, D. M., and Garrett, C. (1972). Immediate effects of intravenous verapamil in cardiac arrhythmias. British Medical fournal, 1, 660.

Scherlag, B. J., Lau, S. H., Helfant, R. H., Berkowitz, W. D., Stein, E., and Damato, A. N. (1969). Catheter technique for recording His bundle activity in man. Circulation, 39, 13.

Singh, B. N., and Vaughan Williams, E. M. (1972). A fourth class of antidysrhythmic action? Effect of verapamil on ouabain toxicity, on atrial and ventricular intracellular potentials, and on other features of cardiac function. Cardiovascular Research, 6, 109.

Requests for reprints to Dr. L. Rydén, Medical Clinic I, Section of Cardiology, Sahlgren's Hospital, S-4I3 45 Göteborg, Sweden. 